\title{
Mathematical Packages Application in The Process of Energy-Saving Technology Development of Metal Structures with Rod Elements Production
}

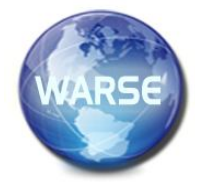

\author{
Ospanova S.M. ${ }^{1}$, ShalamberidzeM. Sh. ${ }^{2}$, LakhnoV.A. ${ }^{3}$, Osypova T. Yu ${ }^{4}$ \\ ${ }^{1}$ Caspian state University of Technologies and Engineering named after of Sh. Esenov, Department of \\ Construction engineering, Aktau, Kazakhstan,ospanova.saltanat@yu.edu.kz \\ ${ }^{2}$ Akaki Tsereteli State University, Faculty of Technical Engineering, Kutaisi, Georgia, \\ marlen.shalamberidze@atsu.edu.ge \\ ${ }^{3}$ National University of Life and Environmental Sciences of Ukraine, \\ Department of Computer systems and networks, Kyiv, Ukraine, lva964@gmail.com \\ ${ }^{4}$ National University of Life and Environmental Sciences of Ukraine, \\ Department of Computer systems and networks, Kyiv, Ukraine, t_osipova@nubip.edu
}

\begin{abstract}
The article further developed the model for determining and choosing rational parameters of welding modes, including welding current, for intersecting round rods used in reinforced concrete building structures. It is shown that the solution to present problem requires computerized support, in particular, using the mathematical package Mathcad. Based on computer modeling, experimental studies, as well as analysis of the process of heating the rods, it was found that the current density in the central part of the contact depends only on the length of the contact between the welded rods, as well as on the length of the contact between the electrodes and the rods. A technique has been developed to determine the compression force between the electrodes in the center of the welding contact, taking into account the required minimum welding current of the crossing round rods. The studies carried out made it possible not only analytically, but by computer modeling (Mathcad and Simufact Welding), to justify the rational parameters of the board temperatures of the materials being welded, in particular, round rods in the welding zone and to ensure the reliability and durability of building reinforced concrete structures.
\end{abstract}

Key words: building structures, core elements, welding modes, energy-saving technology.

\section{INTRODUCTION}

In industrial and civil construction, as well as in the construction of roads and tunnels, reinforced iron concrete structures (ICS) are widely used, especially unstressed ones. These structures are mainly manufactured in the factory, as well as directly at facilities under construction. In ICS rolling rods of low-carbon steel of various profiles (fittings) are used. Also, in non-stressed structures, round rods with a smooth surface of small diameter (up to 10 $\mathrm{mm}$ ) are used. For ICS, metal grids are made of them by means of electric contact welding.

Typically, metal mesh is made of rods of the same diameter, and of rods of different diameters. When electric contact welding of metal grids for ICS, quality control methods are not applied [1]. Only the conformity of the technical properties of the welded rods is checked by the method of tensile testing. When developing the technology of electric contact welding of rods in factories, they try to achieve equal strength of joints corresponding to the base metal. This is achieved by significantly increasing the welding current and by significantly overheating the molten metal in the welding zone.

However, many quality assessment studies show [2], that when tested, samples welded by factory technology were destroyed not by the welded point, but by the base metal [1,2].

Based on the above mentioned, after reaching the melting temperature of the base metal in the welding zone, an increase in the welding current according to the factory technology is impractical.

The design of modern ICS or buildings includes a large volume of various engineering tasks. And the more complex the project, the more design tasks the designer needs to solve. And here it is rather difficult to manage without appropriate computer support.

Today, the work of civil engineers is impossible to imagine without computer technology and a specialized program. Such, for example, include software products such as Simufact Welding, Autodesk Robot Structural Analysis, Midas Civil, SOFiSTiK and others [5].

Currently, computer technology is widely used in welding. Such technologies are effective in the development of mathematical models that allow virtually reproducing technological processes. The use of such models in the design process of welding power sources allows us to predict the technological properties of the source developed for the test phase.

The main advantage of using computer technology in the study of welding production is the possibility of modeling. This will help to study the welding process at its various stages without the cost of real materials and devices.

The basic for modeling the welding process using computer technology is a computer experiment.

The cycle of a computer experiment is divided into several stages. First, they determine the goals of modeling, analyze the object under study, build its model. First, create a physical one, in which the distribution of the characteristics of the object (factors affecting the welding process) is fixed on the essential and non-essential, which at this stage of the study are rejected. 
At the same time, an assumption, or framework for the application of the model, is determined in which the results obtained will have content.

Characteristics of an object are described in a particular language, in particular, using mathematical terms. Further, a preliminary analysis of the model is carried out: they find out whether the welding task is correctly posed, whether it is possible to carry out welding under specified conditions, is the welding process safe, etc.

At the second stage of computer modeling, you can use (if any) a ready-made tool, for example, a computer mathematics system, otherwise you should develop an algorithm for the welding process.

As a rule, many computational algorithms for one welding task can be given. To determine the best, criteria should be formulated to assess the quality of the computational welding algorithm. The third stage is the implementation of the developed algorithm using computer tools: application programs or a programming language.

The fourth stage is dedicated to computing on a computer. This is the stage of the computational experiment, when its similarity with the full-scale experiment is most clearly manifested. Only if in the laboratory an experimenter with the help of a specially constructed setup "asks a question" to nature, then specialists from a computational experiment using a computer pose these questions to mathematical models.

After this, the prediction stage begins when the behavior of the object, process or phenomenon under study is envisaged using a computer model under conditions in which the experiment has not yet passed or in which it is impossible to conduct.

During the last stage, the welding results are processed, they are comprehensively analyzed, conclusions are drawn.

The use of computer technology for the study of weldingobjects allows us to solve the problem of the financial part or the impossibility of conducting a physical experiment, which can often give unpredictable results.

The logic and formalization of computer models allows us to identify the main factors that determine the properties of the studied original object used in welding, in particular, to study the reaction of physical changes in materials and their parameters depending on the initial conditions, as well as the features of the welding environment.

Note that in everyday practice, the usual mathematical packages familiar to any qualified builder and engineer, for example, such as Mathcad, Matlab, SciLab, LabVIEW and others. These mathematical packages and software products not only allow you to automate complex calculations, but are also quite suitable for primary data analysis and visualization.

Thus, taking into account the above facts, in our opinion, it is quite relevant engineering and scientific task to consider issues related to the continuation of research in the field of development of energy-saving technologies for the electrical contact welding of intersecting rods for iron concrete building structures.

In particular, the development task remains relevant, models for determining and choosing rational parameters of welding modes, including welding current.

The last task certainly needs computerized support, for example, based on the use of such common mathematical packages as Mathcad и MatLab. These studies will allow not only analytically and experimentally, but also by computer modeling, to substantiate the rational parameters of the board temperatures of the materials being welded in the welding zone and to ensure the reliability and durability of the structure.

\section{REVIEW AND ANALYSIS OF PREVIOUS STUDIES}

It was shown in [1-3] that despite the fact that currently the technology of bath welding has reached a high level, the probability of defects in welded joints of iron concrete structures made in the conditions of the installation site is quite high [4]. However, the relationship between the use of information technology and related software and the complexity of various calculation parameters for welded joints of iron concrete was not traced.

It was shown in the work [6-8] that the shape and dimensions of the reinforcement of the weld, the radii of the transition from the reinforcement to the base metal in the butt joints of the reinforcement have a significant effect on the concentration of stresses and when a combination of adverse factors (low temperature, residual stresses, unfavorable zone structure thermal effects) can cause fragile structural damage. The data were obtained on the basis of experimental studies and the use of specialized packages for computer modeling was not considered.

A significant contribution to the development of issues of the strength of welded joints was made by the work[914].

In the work [15-17], practical aspects of using various software packages to describe the stress-strain state of welded structures metal were considered. However, only specialized software was considered, which is not always advisable.

Though, as the analysis of most of the reviewed publications has shown, it has been empirically proven that the heat affected zone decreases plasticity and increases brittleness, as a result of which mechanical damage to the welding zone results in destruction of the material being welded in this zone, rather than the place of welding.

On the other hand, as was shown in the work [18], the energy loss due to bursts is the cause of the nonlinearity of the dependence. Therefore, it becomes necessary to control the quality of the strength of the welded joint so that timely adjustment of the welding current is possible in case of obtaining a welded joint with unacceptable strength. We also note that for the calculation, subsequent analysis and visualization of the results obtained, for example, the smallest current required for electric contact welding of intersecting round rods and the compression force, taking into account the smallest current necessary for welding, the possibilities of such packages as Mathcad и MatLab[19, 20]. The latter led to the relevance of our research.

\section{THE PURPOSE}

The purpose of the work is to justify using various research methods, including relying on computer simulation methods widely used in recent years, energysaving technologies for electric contact welding of metal structures. The task is considered in the context of determining the lowest value of the welding current necessary to ensure maximum strength during welding. To 
achieve the goals of the work, it is necessary to solve the following tasks:

1. To develop criteria for assessing the quality of welding of intersecting round bars.

2. To investigate the nature of the change in the heating temperature during electrical contact welding of intersecting round rods.

3. To develop a methodology for determining the smallest current required for welding intersecting round rods, as well as a method for determining the compression force taking into account the smallest current required for electric contact welding of intersecting round rods.

4. Carry out computer computational experiments and full-scale studies on prototypes to confirm the adequacy of the proposed models and methods.

\section{METHODS AND MODELS}

In building non-stressed iron concrete structures, both tearing and shearing forces act on the welded joint due to the physicmechanical effects of concrete. With this criterion of the quality of resistance welding of reinforcing bars, the results of calculations or computer simulations, as well as mechanical tests for separation and shear can be related.

Among these, the most appropriate test design is selected based on its sensitivity to changes in the main factors of the welding process. As such a factor when welding reinforcing bars crosswise (see Figure 1) welding current was selected, which significantly affects the strength of the welded joint. Therefore, the sensitivity of the test circuit to a change in this parameter is chosen as a criterion for choosing a quality indicator.

The criterion for evaluating the sensitivity of the test circuits was the correlation coefficient between the strength of the welded joint and the welding current. As a result of the correlation analysis of the data obtained during the modeling process in MathCad, as well as the experiments performed, it was found that when welding intersecting round bars, the quality criterion is the results of the test of welded joints for shear.

The research also considers the features of the development of energy-saving technology for the manufacture of metal structures in iron concrete structures.

For electric contact welding of samples of metal structures (mesh), the same values of the parameters of the welding mode were applied (twel=4sec, Fsec=300 daN, Isec $m x=4 \kappa A$ ), mesh of intersecting round rods with dimensions of $5+3 \mathrm{~mm}$. The relationship between the strength of electrical contact welding of the metal mesh and the welding current is shown in Figure 2.

The graph shows that with an increase in current to 2.4 $\kappa \mathrm{A}$, the strength of the welded joint increases linearly.

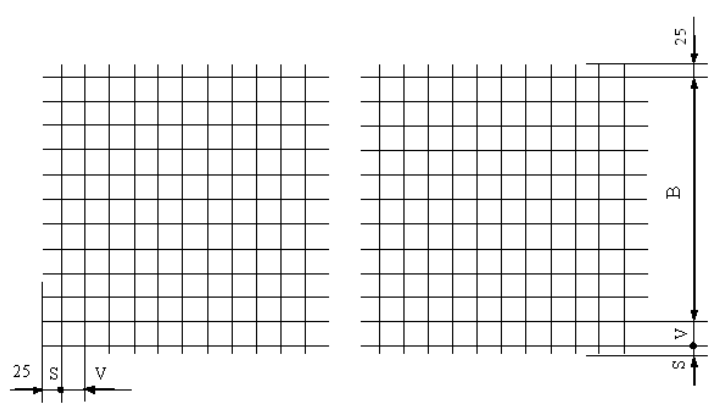

Figure 1: Welded metal mesh used in non-stressed reinforced concrete structures

In the VD section, with an increase in current from 2.4 to $4.0 \mathrm{kA}$, the strength increases slightly - from 33 to 35 daN, i.e. an increase of current of $80 \%$ increases the strength by $30 \%$.

The analysis of strength and the nature of the fracture of welded samples shows that with an increase in current of more than $2.4 \mathrm{kA}$, welded samples are destroyed by the base metal. The dispersion of the strength of the welded samples corresponds to the dispersion of the strength of the welded material.

In addition, an external examination of welded joints shows that there is an increase in extruded expanded metal from the weld zone.

All this indicates that: overheating of the metal in the welding zone above the melting temperature of the material being welded leads to a deterioration in the mechanical properties of the material and an increase in the volume of superheated metal extruded from the welding zone, i.e. electric contact welding of intersecting rods was carried out at a welding current that ensures that the melting temperature of the material being welded is achieved in the contact zone, which will save energy without compromising the strength of the welded joint.

Pilot studies of the heating process in the contact welding of intersecting round rods and a theoretical study of the heating of the rods were carried out daN.

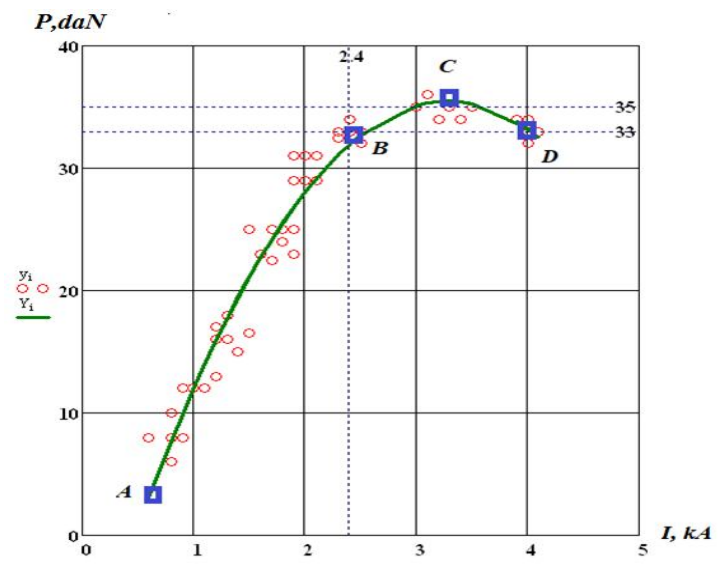

Figure 2: The relationship between the strength of electrical contact welding of a metal mesh and welding current 
In an experimental study of the process of heating the welded rods, the temperature was measured at three points of these, two points $(1,2)$ were located near the contact from the side of each welded rod, and the third point was near the lower electrode (Figure 3)

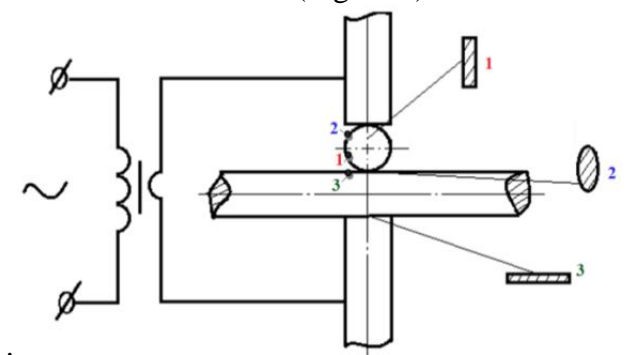

Figure 3: The location of the points at which the temperature was measured during welding

For temperature oscillography, thermocouples were welded to the samples at the indicated points by capacitor welding. The experimental results are presented in Figure 4 and Figure 5.

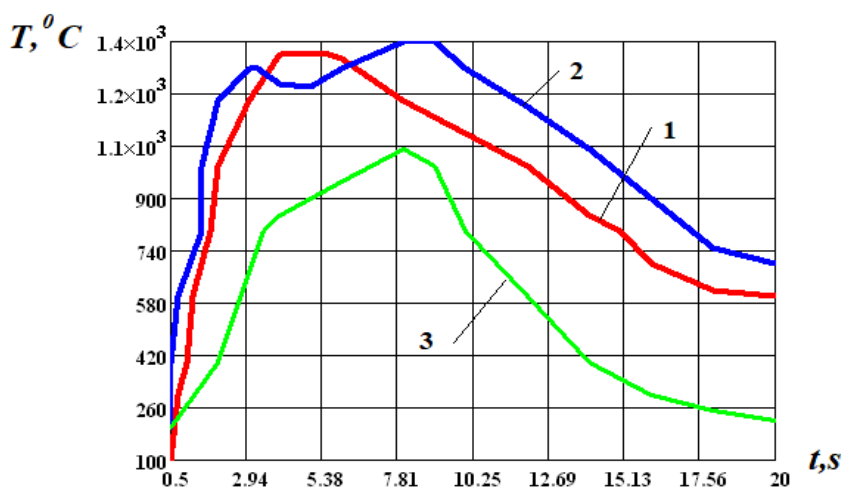

Figure 4: The thermal cycle of various points of the welded sample (soft mode)

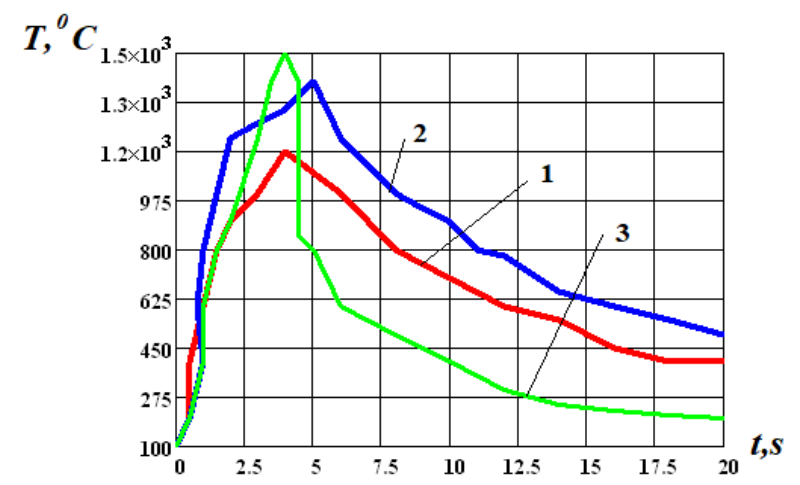

Figure 5: The thermal cycle of various points of the welded sample (hard mode)

As the simulation results and the subsequent experimental verification showed, the highest heating rate at the beginning of the process is observed at the points located in the area of the welding contact (points 1 (red line), 2 (blue line)). At point 3 (green line), located near the electrode, on the surface of the rod of a larger cross section, the heating rate is somewhat lower. Characteristic of this experiment is the formation of a site of almost constant temperatures on the thermal cycle curves of those points that are in the region of greatest heating of points 1 , 2. Obviously, at a certain stage of the welding process, in the region adjacent to point 3 , thermal equilibrium sets in, at wherein the heat release due to the current is balanced by heat removal due to heat conduction. The temperature of the points of this region almost does not increase in the future. With correctly selected mode parameters, in combination with the force on the electrodes, the steadystate thermal state should correspond to the heating of the contact points to the melting temperature.

An excessively large force on the electrodes with insufficient current will reduce the current density in the welding contact and the equilibrium state will come before the required temperature in the welding zone is reached, which will lead to lack of penetration.

Thus, the level of the equilibrium area on the curves of the thermal cycle is controlled by a change in the electrical parameters in combination with the compressive force.

Determination of the optimum value of the welding current and the compression force implies the determination of their lowest value, which ensures obtaining the equilibrium area corresponding to the melting temperature of the material of the welded rods.

From Figure 4 and Figure 5 show that these currents and compressive forces lead to severe overheating of the metal of a rod of small diameter; therefore, when welding rods of different diameters, determination of the welding mode parameters is necessary for a rod of small diameter.

As a result of a theoretical study and analysis of the process of heating rods, dependence is obtained for calculating the smallest current required for welding rods

$$
\theta_{\infty}(\vartheta)=\frac{\cos [\mu(1-v)]}{\cos \mu}-1
$$

i.e. limited temperature range $\theta_{\infty}(\vartheta)$, determined by the condition

$\cos \mu$

where $\quad \mu=\frac{I_{2}}{2 \pi r_{o t}} \sqrt{0,24 \frac{\beta \rho_{o}}{\lambda}}-$ dimensionless parameter characterizing the intensity of heat sources; $\rho_{0}$ initial resistivity of the core material; $\lambda$ - coefficient of thermal conductivity of the $\operatorname{rod} ; \beta-$ temperature coefficient;

$$
\theta_{\infty}=\beta T_{\infty}-\text { dimensionless temperature. }
$$

In the course of research, the process of curing the rods by cold contact and during the welding process was also considered.

Such studies are necessary to determine the current density and compression force during welding. 
It was experimentally established that with a cold hug, the specific pressure is practically constant and amounts to about 0.6 of the Brunel hardness for this material:

$$
k \approx 0,6 \cdot H B
$$

Cold creep experiments on rods of small diameter (up to $5 \mathrm{~mm}$ ) show that the specific pressure is

$$
k \approx 1,28 \cdot H B
$$

Upsetting rods were also investigated during welding. Figure 6 shows the changes in draft and the average value of the draft during welding. Less intense increase in draft occurs when welding in soft mode. The average upsetting time during welding is $0.25 \mathrm{~mm} / \mathrm{s}$ when welding in soft mode "a" (zone with inclined hatching), and when welding in hard mode "b" (zone with vertical hatching) $-0.57 \mathrm{~mm}$ /s Accordingly, when welding in soft mode, the volume of metal more overheated and squeezed out of the welding zone is greater, i.e. when welding in soft mode, part of the energy spent on heating the welding zone is lost and does not participate in the formation of a welded joint. Therefore, in order to save electricity, we proposed that the contact welding of intersecting rods be carried out in hard mode.

After turning off the current under the action of the force $\mathrm{P}$, the deposit continues to increase, and a more prolonged, albeit less intense growth of the precipitate is observed in rods welded in a softer mode. In samples welded in hard mode, the rate of increase in precipitation decreases significantly after $1-1.5$ seconds after turning off the current, and after 5-6 seconds, plastic deformation in the zone of the welding contact practically ceases.

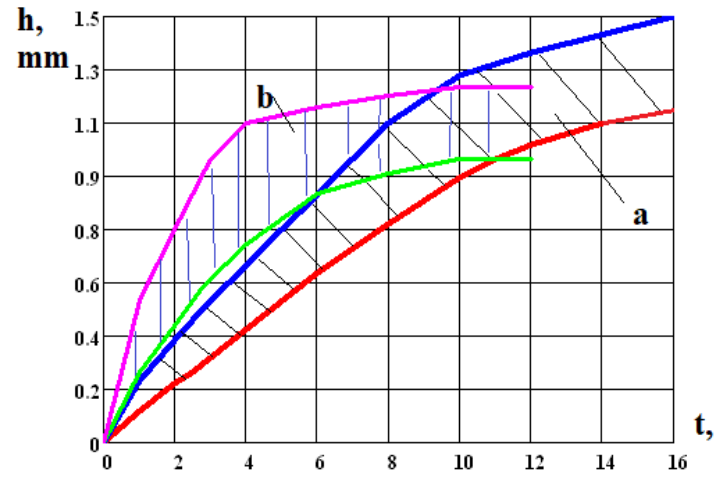

Figure 6: The change in the settlement of the rods during the welding

Apparently during soft welding in the welding zone, the amount of molten metal is greater, respectively, the volume of extruded metal is larger.

This is confirmed by external inspection of welded joints. Thus, when welding in soft mode, part of the energy spent on heating the welding zone is not consumed to form a welded joint. Therefore, in order to save electricity, it is advisable to conduct electrical contact welding of crossed rods in hard mode. In another series of experiments, in addition to precipitation, the welding current and temperature were measured and recorded at individual points of the welded sample during the welding process.

Apparently during soft welding in the welding zone, the amount of molten metal is greater, respectively, the volume of extruded metal is larger. This is confirmed by external inspection of welded joints. Thus, when welding in soft mode, part of the energy spent on heating the welding zone is not consumed to form a welded joint.

Therefore, in order to save electricity, it is advisable to conduct electrical contact welding of crossed rods in hard mode. In another series of experiments, in addition to precipitation, the welding current and temperature were measured and recorded at individual points of the welded sample during the welding process.

According to the average draft, in these experiments, the projection area of the welding contact Fsv. The average draft $h$ and the average area Fsv are plotted on the graphs (Fig. 3.8), from which it can be seen that at the end of the welding process, when the current is turned off, the area of the weld point is the maximum value.

When welding in hard mode, the precipitation rate is the highest at the beginning of the process, it falls during the entire welding process. At a pressure in the welding contact of about $2.5 \mathrm{Dan} / \mathrm{mm}^{2}$, even before the current is turned off, there is a sharp decrease in the draft rate from 0.5 to $0.3 \mathrm{~mm} / \mathrm{s}$.

The moment the current is turned off is about 1.5 Dan / $\mathrm{mm}^{2}$. After turning off the current, the sediment continues for 5-6 seconds, however, the precipitation rate is so low that the pressure in the contact practically does not decrease.

For further growth of precipitation, efforts are required greater than for precipitation of samples welded in a softer mode.

The specific pressure at the point of contact of the rods at this moment is $1.5-1.6 \mathrm{dan} / \mathrm{mm} 2$. In the future, the specific pressure drops even more due to an increase in the sizes of the contact area of the rods, and the yield stress of the near-contact zone decreases with cooling and temperature equalization, i.e. conditions for the further development of rainfall are becoming less and less favorable.

The required maximum temperature in the welding contact is equal to the melting temperature of the metal being welded:

$$
T_{\max }=\frac{1}{\beta} \cdot \theta_{\max },
$$

where $\theta_{\max }-$ maximum dimensionless temperature;

$$
\beta \text { - temperature coefficient, } 1 /{ }^{\circ} \mathrm{C} \text {. }
$$

Then we can prove that

$$
\theta_{\max }=\frac{1-\cos \mu}{\cos \mu},
$$

and

$$
T_{\max }=\frac{1}{\beta} \cdot \frac{1-\cos \varpi}{\cos \mu}
$$




$$
\mu=\arccos \frac{1}{1+\mu \cdot T_{\max }} .
$$

Substituting $\mu$, we get

$$
\frac{I_{c b}}{2 \pi\left(r_{0 t}\right) p r} \sqrt{\frac{0,24 \beta \rho_{0}}{\lambda}}==\arccos \frac{1}{1+\beta T_{\max }},(8)
$$

where $F_{p r}=2 \cdot \pi \cdot\left(r_{0 t}\right)^{2}$ pr and $\mathrm{m}-$ area ratio $F_{p r}$ to the cross-sectional area of the rods $\frac{\pi d_{1}^{2}}{4}$.

The value of $\mathrm{m}$ is established empirically. The larger $\mathrm{m}$, the relatively later the limit state in the contact occurs, the higher the current required for welding. To calculate the required maximum current, we obtain

$$
\begin{aligned}
& I_{c b}=\pi d_{1} \sqrt{\frac{m}{2} \cdot \frac{\lambda}{0,24 \cdot \beta \rho_{0}}} \times \\
& \times \arccos \frac{1}{1+\beta T_{\max }} .
\end{aligned}
$$

This chapter presents a method for determining the current density and shows that for given sizes of contact pads, the current density of the rod depends on the longitudinal dimensions of the pads $\left(\xi_{1}\right.$ and $\left.\xi_{2}\right)$, and transverse dimensions $\left(\varphi_{1} r_{0}\right.$ и $\left.\varphi_{2} r_{0}\right)$ can be neglected

$$
\begin{aligned}
& j_{0}\left(\xi_{1}, \xi_{2}\right)=\frac{1}{2 \cdot \pi^{2} \cdot r_{0}^{2}} \times \\
& \times\left[\frac{P\left(\xi_{1}\right)}{\xi_{1}}+\frac{P\left(\xi_{2}\right)}{\xi_{2}}\right],
\end{aligned}
$$

Values $\frac{P\left(\xi_{1}\right)}{\xi_{1}}, \frac{P\left(\xi_{2}\right)}{\xi_{2}}$ taken from Figure 7 .

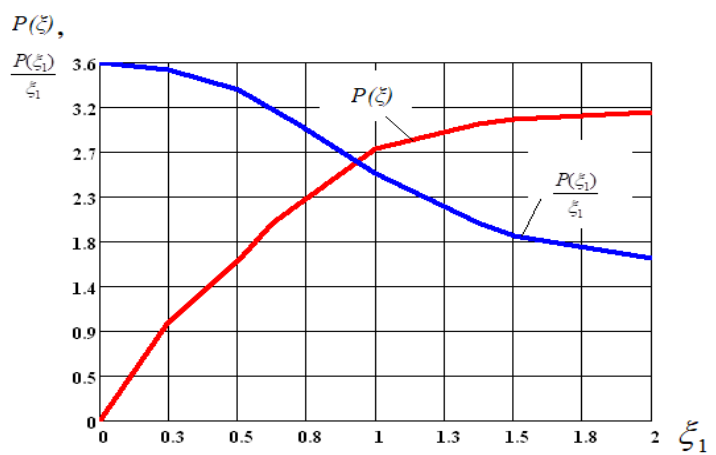

Figure 7: The relationship between $P(\xi)$ and $\xi_{1}$
Knowing the current density, you can determine the lowest required value of effort. In this case, the specific pressure in the contact zone during welding

$$
K=\frac{P}{F}, \quad \mathrm{daN} / \mathrm{cm},
$$

where $F=\frac{i}{j}-$ calculated value in the contact zone

Thus,

$$
P=K \cdot F
$$

\section{DISCUSSION}

The conducted studies made it possible not only analytically, but by means of computer modeling, to justify the rational parameters of the board temperatures of the materials being welded, in particular, round rods in the welding zone. Thus, it is possible to significantly increase the reliability and durability of building reinforced concrete structures.

During the experimental verification of the developed models, the following was established: he sizes and shape of the contact depend on the size and shape of the rods and electrodes, as well as on the compression force between the electrodes;

the contact area between the welded rods depends on the draft during welding Fwel(h) and with a cold embrace of the rods Fwel $(\mathrm{h})=1,8 \mathrm{Fx}(\mathrm{h})$; when welding rods in the contact zone, the specific pressure is constant and depends on the hardness of the material of the rods, when welding rods with diameters greater than $10 \mathrm{~mm}-K \approx 0,6 \mathrm{HB}$; and when welding rods of small diameter (up to $5 \mathrm{~mm}$ ) $K \approx 1,28 H B$.

The necessary heating rates take place in the initial stage of the welding process. The point of the near-contact region is heated to the melting temperature of the base metal for 1.5-2 seconds. The limiting temperature of the points of the near-contact region from the side of the small rod is $100-150^{\circ} \mathrm{C}$ higher than from the side of the large rod.

The studies made it possible to integrate the obtained results, as well as models in Mathcad [20] and MatLab, into professionally oriented software products, in particular, into the Simufact Welding program, see Fig. 8, 9. Moreover, the results obtained in Mathcad can be imported into Simufact Welding using a CSV file with the coordinates of the welding path.

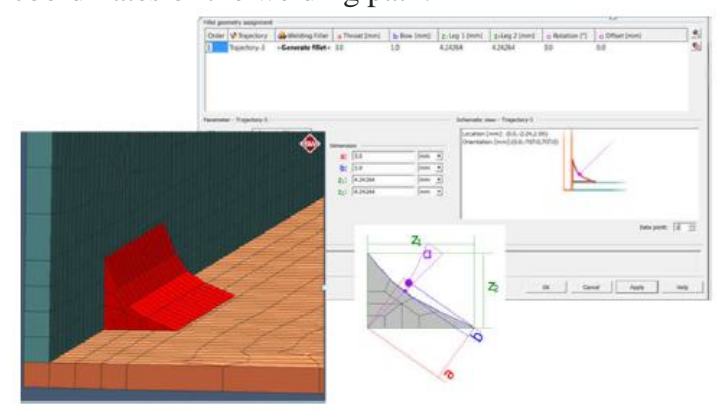

Figure 8: An example of using the obtained research results in the program SimufactWelding 
Note that in order to obtain more realistic results, calibration of virtual heat sources is required. In fig. Figure 9 shows an example of the results of calculation and modeling of the weld section.

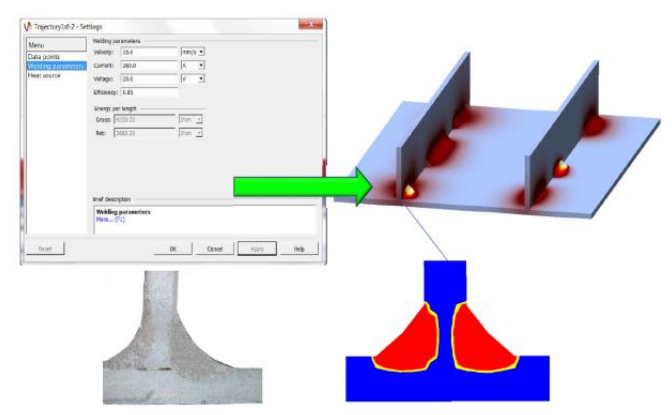

a) Example of calibration of a virtual heat source

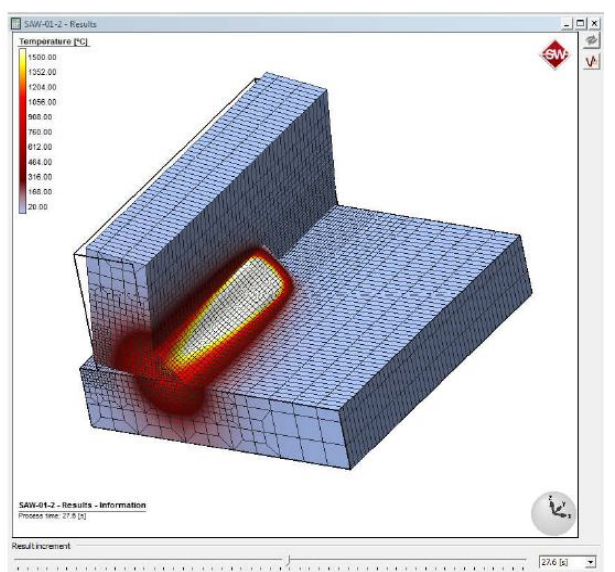

b) An example of the visualization of the weld

Figure 9: An example of calibrating a virtual heat source in the Simufact Welding program for a weld to select rational parameters for welding conditions

A definite drawback of research at this stage of work is the relatively small amount of experiments at real construction sites. This is due to the fact that the main emphasis in the work was made on the use of computer modeling in the development of energy-saving technology for the manufacture of metal structures with core elements. As the research continues, we plan to significantly expand the number of real construction projects, on which the developed methodology was implemented and tested in real-life conditions for reinforced concrete structures.

\section{CONCLUSION}

The model was further developed to determine and select rational parameters of welding modes, including welding current, for intersecting round rods used in reinforced concrete building structures. It is shown that the solution to this problem needs computerized support, in particular, by using the mathematical package Mathcad. The

studies carried out made it possible not only analytically, but by computer modeling, to justify the rational parameters of the board temperatures of the materials being welded, in particular, round rods in the welding zone and to ensure the reliability and durability of building reinforced concrete structures. During the experimental verification of the developed models, it was found that: the size and shape of the contact depend on the size and shape of the rods and electrodes, as well as on the compression force between the electrodes; the contact area between the welded rods depends on the draft during welding Fwel(h) and with a cold embrace of the rods Fwel(h) $=1,8 \mathrm{Fx}(\mathrm{h})$; when welding rods in the contact zone, the specific pressure is constant and depends on the hardness of the material of the rods, when welding rods with diameters of more than $10 \mathrm{~mm}-K \approx 0,6 \mathrm{HB}$ and when welding rods of small diameter (up to $5 \mathrm{~mm}$ ) $K \approx 1,28 H B$.

The pattern of temperature changes in the welding zone is experimentally determined. It was revealed that the necessary heating rates take place in the initial stage of the process. The point of the near-contact region is heated to the melting temperature of the base metal for 1.5-2 seconds. The limiting temperature of the points of the nearcontact region from the side of the small rod is $100-150^{\circ} \mathrm{C}$ higher than from the side of the large rod. It was found that the longer the welding time, the less the effect of the heating process. At this current value, it is proposed to weld the intersecting round rods in hard mode $\left(\mathrm{t}_{\mathrm{CB}}<4 \mathrm{sec}\right)$.

Based on the analysis of the process of heating the rods, it was found that the current density in the central part of the contact depends only on the contact length between the welded rods, as well as on the contact length between the electrodes and the rods.

Based on the computer simulation, as well as comparing the experimental data with the results of calculating the temperature of the near-contact region in the limiting state, a technique is proposed for determining the smallest current required for welding the rods.

The obtained research results made it possible to integrate the experimental data obtained, as well as models in Mathcad and MatLab, into a professionally oriented software product -Simufact Welding. Data is imported into Simufact Welding by means of a CSV file with the coordinates of the welding path.

A technique has been developed to determine the compression force between the electrodes in the center of the welding contact, taking into account the required minimum welding current of the crossing round rods.

\section{REFERENCES}

1. Baran, M., \&Tankut, T. (2011). Experimental Study on Seismic Strengthening of Reinforced Concrete Frames by Precast Concrete Panels. ACI Structural Journal, 108(2).

https://doi.org/10.14359/51664258

2. Su, R. K. L., \& Zhu, Y. (2005). Experimental and numerical studies of external steel plate strengthened reinforced concrete coupling beams. Engineering structures, 27(10), 1537-1550.

http://dx.doi.org/10.1016/j.engstruct.2005.04.012

3. Engindeniz, M., Kahn, L. F., \& Abdul-Hamid, Z. (2005). Repair and strengthening of reinforced concrete beam-column joints: State of the art. ACI structural 
journal, 102(2), 1.

https://doi.org/10.14359/14269

4. Teng, J. G., Yu, T., \& Fernando, D. (2012). Strengthening of steel structures with fiber-reinforced polymer composites. Journal of Constructional Steel Research, 78, pp. 131-143. https://doi.org/10.1016/j.jcsr.2012.06.011

5. Barazzetti, L., Banfi, F., Brumana, R., Gusmeroli, G., Previtali, M., \&Schiantarelli, G. (2015). Cloud-to-BIM-toFEM: Structural simulation with accurate historic BIM from laser scans. Simulation Modelling Practice and Theory, 57, pp. 71-87. https://10.1016/j.simpat.2015.06.004

6. Teng, J. G., Yu, T., \& Fernando, D. (2012). Strengthening of steel structures with fiber-reinforced polymer composites. Journal of Constructional Steel Research, 78, pp. 131-143. https://doi.org/10.1016/j.jcsr.2012.06.011

7. Sahoo, D. R., \& Rai, D. C. (2010). Seismic strengthening of non-ductile reinforced concrete frames using aluminum shear links as energy-dissipation devices. Engineering Structures, 32(11), pp. 3548-3557. https://10.1016/j.engstruct.2010.07.023

8. Schiavinato, L., Colombelli, S., Eccher, G., Nave, D.,Cucino, P., \& Bona, N. (2016). BIM use in the infrastructural field: the case of the extension of the railway in the underground track of Catania, from the Central Station FS to the airport. In ITA-AITES World Tunnel Congress, San Francisco, CA, pp. 1917-1925.

9. Carrillo, J., Rico, A., \&Alcocer, S. (2016). Experimental study on the mechanical properties of welded-wire meshes for concrete reinforcement in Mexico City. Construction and Building Materials, 127, pp. 663672.

https://doi.org/10.1016/j.conbuildmat.2016.10.011

10. Radaj, D. (2016). Fatigue assessment of welded joins by local approaches. Cambridge: Abington publishing, 1998. - 461 .

11. Ghods, P., Isgor, O. B., McRae, G., \& Miller, T. (2009). The effect of concrete pore solution composition on the quality of passive oxide films on black steel reinforcement. Cement and Concrete Composites, 31(1), pp. $2-11$.

https://doi.org/10.1016/j.cemconcomp.2008.10.003

12. Chung, D. D. L. (2001). Structural health monitoring by electrical resistance measurement. Smart materials and structures, 10(4), 624.

https://doi.org/10.1088/0964-1726/10/4/305

13. Cherkas, A., \&Rimshin, V. (2017). Application of composite reinforcement for modernization of buildings and structures.In MATEC Web of Conferences.EDP Sciences.117, 27.

14. Julio, E. S., Branco, F., \& Silva, V. D. (2003). Structural rehabilitation of columns with reinforced concrete jacketing. Progress in Structural Engineering and Materials, 5(1), pp. 29-37.

https://doi.org/10.1002/pse. 140

15. Lutomirska, M., \&Lutomirski, S. (2016). Design and construction errors resulting in lack of tightness of reinforced concrete structures. Zeszytynaukowe, 39.

16. Lopez-Inojosa, A. A. (2006). Field evaluation of composite materials for bridge strengthening. University of Missouri-Rolla.
17. Jordanov, M., Marinov, M., \&Krutzik, N. (2001). Seismic response analysis and upgrading design of pump houses of Kozloduy NPP units 5 and 6.

18. Ospanova S., Zivzivadze L., \&Shalamberidze M. K. (2015).

Voprosurazrabotkienergosberegayushejtehnologiisvarkiar maturyizperekreshivayushihsyakruglyhsterzhnej. III Mezhdunarodnayanauchnayakonferenciya «Energetika: regionalnyeproblemyiperspektivyrazvitiya», Kutaisi, 2015, pp. 237-241.

19. Baisarova, G. Brzhanov, R., Kikvidze, O.G., et al. (2019). Computer simulation of large displacements of thermoelastic rods, Journal of Theoretical and Applied Information Technology, 97(15), pp. 4188-4201.

20. Bulekbaeva G., Kikvidze O.G., Lakhno V., Brzhanov R., Tabylov A., Smirnov S. (2019). Computer simulation in the mathcad package of plastic deformation of the deposited layer on the flat surface of the part, Journal of Theoretical and Applied Information Technology, Vol.97. No 20, pp. 2467-2484. 